Revista de la red interuniversitaria de estudios sobre las literaturas rioplatenses contemporáneas en Francia

$8 \mid 2013$

Argentina y Uruguay: lecturas del país vecino en la literatura rioplatense contemporánea (siglos XX y XXI)

\title{
Ningún invento
}

\section{Mariano García}

\section{CpenEdition}

\section{Journals}

\section{Edición electrónica}

URL: http://journals.openedition.org/lirico/1016

DOI: $10.4000 /$ lirico.1016

ISSN: 2262-8339

\section{Editor}

Réseau interuniversitaire d'étude des littératures contemporaines du Río de la Plata

Referencia electrónica

Mariano García, « Ningún invento », Cuadernos LIRICO [En línea], 8 | 2013, Publicado el 01 enero 2013 consultado el 21 septiembre 2020. URL : http://journals.openedition.org/lirico/1016 ; DOI : https:// doi.org/10.4000/lirico.1016

Este documento fue generado automáticamente el 21 septiembre 2020

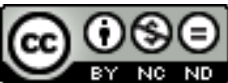

Cuadernos LIRICO está distribuido bajo una Licencia Creative Commons Atribución-NoComercialSinDerivar 4.0 Internacional 


\title{
Ningún invento
}

\author{
Mariano García
}

\section{REFERENCIA}

José Fraguas y Eduardo Muslip (compiladores), Decirlo todo: escritura y negatividad en Carlos Correas, Córdoba, Los Polvorines, Universidad Nacional de General Sarmiento, 2011, 255 páginas

Carlos Correas, La manía argentina, Prólogo de José Fraguas y epílogo de Carlos Surghi, Córdoba, Los Polvorines, Universidad Nacional de Córdoba, 2011, 137 páginas

Carlos Correas, Los jóvenes y otros cuentos, postfacio de José Fraguas y Eduardo Muslip, Buenos Aires, Mansalva, 2012, 126 páginas 
Como suele ocurrir con los escritores malditos, no parece fácil acercarse a la figura de Carlos Correas sin hacer alguna mención a su vida; las constantes alusiones autobiográficas tanto en sus ficciones como en sus ensayos generan en gran medida esta presunción, al punto que uno siente que en esa escritura brillante hay muy poca "literaturidad" si por eso entendemos invención. Todo lo saca Correas de la realidad: nada parece que pueda ser inventado. La fijeza alucinatoria de su realismo está dada por su pavorosa capacidad para encontrar el

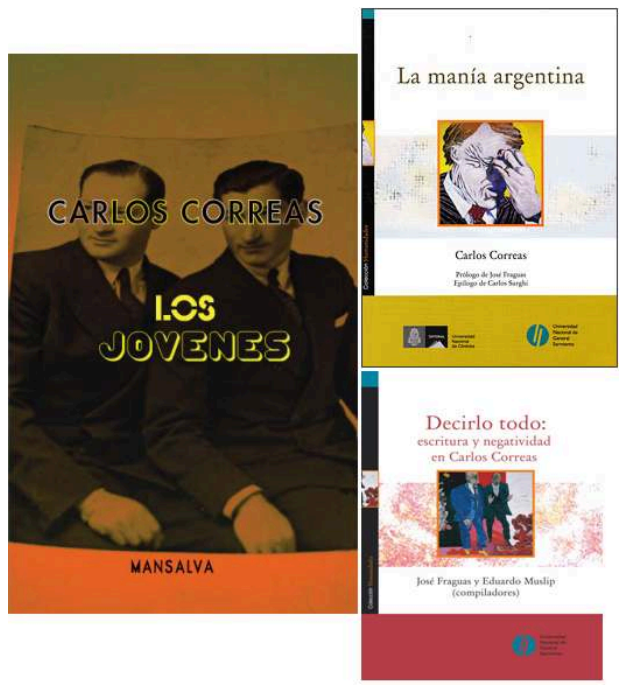
mot juste. Eso no lo convierte en un avatar anacrónico y mucho menos melancólico del realismo porque la articulación de los datos de la realidad no obedece en él a una construcción narrativa sino filosófica, a la manera de Gombrowicz, si se quiere, aunque fuera de eso no se parecen en nada. "Me postergaba a mí mismo para madurar", dice su alter ego Félix Chaneton, "todo lo había apostado al momento de mi madurez": proyecto, como se ve, en las antípodas de aquel del polaco.

2 Tan poco literaria parece su obra de ficción que las influencias, en el caso de existir, aparecen invocadas como espectros, no de manera concreta en el estilo ni en los temas, salvo quizá por cierto regodeo perverso en la sumisión o en la humillación que remite a sus referentes fundamentales, Arlt y Genet, y al imaginario existencialista que hunde sus raíces en Kierkegaard. En el caso de encontrarnos con citas, éstas pertenecen a frases o diálogos del cine, la televisión o algunas canciones de moda. Por sobre todas las cosas, en la experiencia que propone Correas prevalece lo discontinuo, esa forma correosa de lo negativo : el rechazo al continuo como idea que todo lo abarca y todo lo comprende, el continuo como forma burguesa de la inclusión, el continuo como conformidad y facilidad. ¿Eso basta para convertirse en un maldito ? Digamos que la voluntaria marginación de la escena intelectual, tras haber formado parte en los años 50 del "trío existencialista" junto con sus entonces amigos Oscar Masotta (que puede arrogarse la introducción en Argentina y España del lacanismo) y Juan José Sebreli (que desarrollará una carrera progresivamente visible y mediática) es un elemento, que se suma al juicio por obscenidad que sufre tras la publicación de su relato "La narración de la Historia"; su homosexualidad torturada y su propia "normalización" que lo lleva a las mujeres y a cátedras universitarias son más elementos; sus historias con travestis cuando se muda en los últimos años cerca de Plaza Once y su elocuente suicidio en 2000 son otros tantos aspectos anecdóticos que no aspirarían a la densidad del malditismo si no fueran tematizados y frecuentados por los propios escritos de Correas. Sobrevolando todo ello, Correas mantiene intacto en toda su obra el poder provocador, inquietante y corrosivo del verdadero filósofo que escupe la verdad sin medias tintas.

3 Los jóvenes y otros cuentos reúne cuatro relatos que cubren presumiblemente el largo periodo vital en el que Correas escribió. El relato "Los jóvenes" lleva un prólogo suyo fechado en marzo de 1953 y se asume como continuación de otro texto que un amigo, Jorge Masciángoli, habría escrito en 1952. Le sigue "La narración de la Historia", el 
texto del escándalo por el cual el autor, el director de la revista Centro Jorge Lafforgue y el comité de redacción fueron procesados en 1959 y que habría motivado la escasa frecuencia de Correas para publicar ficción. "Las armas tiernas" es un relato poco conocido aportado por Sebreli al diario Perfil en 2007. Por último, "Algo más sobre mi caso" fue publicado por el autor en la revista La caja negra y reditado como "Él y ella" en su libro Ensayos de tolerancia de 1996.

"Los jóvenes", dado a conocer por Jorge Lafforgue ${ }^{1}$, le fue entregado a éste por Bernardo Carey, a quien Correas había confiado un texto del que temía la publicación tras el proceso por inmoralidad suscitado por "La narración de la Historia" y del que luego se desentendió u olvidó. Compartiría, según sus editores Muslip y Fraguas ( $L J$ 122), los aspectos estéticos de textos extraviados como el artículo sobre el valor erótico y político del "cabecita negra" (escrito tras el golpe de 1955 y rechazado por Contorno) o su diario íntimo, que llevó durante toda la vida y que por el momento se considera perdido o retenido por su familia. Sin embargo, el estilo carnavalesco, desbordado, esperpéntico, así como el recurso del monólogo interior seguramente novedoso y vanguardista para la Buenos Aires de comienzos de los años 50, no guarda mucha relación con la narración adusta, seca, levemente displicente, levemente asqueada del mundo, que se convertiría en lo característico de su escritura y que ejemplifican muy bien "Las armas tiernas" o Los reportajes de Félix Chaneton. Hay en este texto à clef una serie de alusiones y chistes privados que quedan fuera de las posibilidades de desciframiento -y en última instancia, del interés- del más entusiasta lector, que sigue desconcertado por el carácter mitad privado y mitad -tímidamente- público de esta pantomima de trazo grueso que solo interesa para sopesar la carrera hacia la austeridad expresiva. Más allá de que Correas haya publicado poco, este texto no sólo no era publicable por su contenido sino que no guardaba demasiada relación con la línea de escritura que eligió desarrollar más tarde. El grupo de locas que toma té en el bar Anchor y especula acerca de los machos que pasan, el que es mitad loca-mitad macho y quisiera ser deseado por ellas pero pertenece y no pertenece al grupo, el macho de verdad dispuesto a conformarse con viejos o con prepúberes, son algunos de los temas reconociblemente correístas : el mito narcisista de la juventud, la vejez como decrepitud irredimible, el cinismo de las locas y su artillería verborrágica... La leyenda final de la Princesa y la Momia resume el carácter grotesco centrado en lo bajo corporal, el humor insistentemente escatológico. Los personajes comentan mucho su aburrimiento, siempre en el momento en que el texto en efecto comienza a aburrir y a aburrirse. "Los jóvenes" interesa como fragmento de la marginada vida gay de su época y como documento del desarrollo de Correas como escritor de ficción, pero a primera vista no parece que tenga un valor intrínseco frente a logros tan rotundos como "La narración de la Historia", que le sigue en este volumen, lo que no quita los méritos de este rescate, algo deslucidos por erratas graves (por ejemplo en la p. 75) y una política editorial poco clara para la fijación de los signos diacríticos que por momentos dificulta la comprensión de un texto ya denso. El resto de los relatos es un buen complemento para el volumen Un trabajo en San Roque, que también incluía "La narración de la Historia".

5 La manía argentina se puede considerar un ensayo complementario de La operación Masotta en el tono general de invectiva que recorre su vibrante sintaxis, si bien los reflejos (auto)biográficos de este último están casi ausentes en el título que nos ocupa, y que preocupa mucho, por cierto, a Correas. Por las informaciones que va dejando caer el propio autor, debió comenzar con la escritura de este ensayo poco después de que la 
Argentina entrara en "democracia" (ya explicaremos el uso de las comillas) y de 1983 se extendió por lo menos hasta diciembre de 1986 ; circuló a partir de entonces como inédito entre amigos del autor hasta el momento de este muy significativo rescate editorial. Correas asume aquí la tarea intelectual de analizar determinadas "manías" del ensayo argentino, particularmente encarnadas en su principal bestia negra, el filósofo Víctor Massuh. Para ello (y para comprender la opción de Massuh como intelectual) comienza por analizar el papel de la guerra en la sociedad tras las citas iniciales de discursos de militares argentinos sobre el sentido de lo que ellos consideraban su guerra², así como nociones paratemáticas como "guerrilla", "subversión", "revolución", "terrorismo". Como de costumbre, Correas no tarda en remitir la cuestión a Hegel : "en el momento de la guerra el Estado manifiesta su salud; en la paz, en cambio, no hay más que goce y actividad en lo particular de cada uno [...]. La guerra es esta elevación de la libertad individual, negativa, abstracta (aislada) a la libertad comunitaria, positiva, concreta (compartida)" (MA 25). La noción de terrorismo se enlaza con la de guerra ya que se la concibe como una modalización de la guerra misma, en tanto que la subversión sería una etapa precoz de la revolución. En cuanto al totalitarismo, según el sentido marxista éste se encuentra en conexión interna con el de "democracia" que "puede y tiene que incluir formas dictatoriales (la dictadura del proletariado)" y que "se opone a 'democracia' en el sentido teórico burgués ('gobierno representativo de todos los ciudadanos')" ya que "desde el punto de vista marxista la 'democracia burguesa' es una contradictio in adjecto, una seudodemocracia” (MA 29). Vuelve Carlos Correas sobre el "terrorismo" en la larga y significativa nota $36^{3}$ que culmina con una sentencia lapidaria: "la reflexión sobre el terror en la Argentina recién ha empezado a aprender a hablar" (MA 34).

La base de la manía intelectual argentina aparece enunciada en la página 43 : "la manía que tratamos es, como las psicosis de terror [...], tanto defensa ante la guerra cuanto provisión de una doctrina para la guerra. Y esta doctrina es violenta y de violencia ; adopta necesariamente el partido de la represión armada contra la subversión" (MA 43). Tal es la consecuencia refleja de la "guerra a la guerra" : así como la guerra efectiva produce neurosis de guerra, la guerra como negación de la realidad de la guerra origina en el intelectual de izquierdas una "psicosis de guerra", una irrealización a modo de compensación que Correas ejemplifica con La era del peronismo (1981) de Jorge Abelardo Ramos, y con Los deseos imaginarios del peronismo (1983) de Juan José Sebreli. De ambos, recibe las peores tundas el viejo amigo, que en su libro, una "miserable bazofia pedantesca", "prodiga chismorreos inverificables" (38) entre otras aciagas características. Siguen a esto las iras en nombre del Gramático Correas (así como Masotta merecerá las iras del Traductor del Alemán Correas) en un excurso como mínimo tan pedantesco como peligroso si el lector todavía recuerda que menos de diez páginas atrás el mismo Correas comete una falta elemental en el uso del impersonal ("en ese adelante podrían (o pudieren) haber 'rebrotes terroristas y subversivos", p. 31), y varias más adelante, errores por los cuales a nadie se le ocurriría diagnosticarle a Correas la "disgregación mental" que él le achaca a Sebreli. Menos explicable o más cruel es que atribuya la "deshonestidad intelectual" de Sebreli a su homosexualidad y autodidactismo, cuando el propio Correas se jacta casi en los mismos términos que Sebreli de su no pertenencia a ningún grupo (bien que Correas pertenecía velis nolis a la academia) y cuando se podría hablar en el caso de Carlos Correas de una "psicosis de guerra" que lo llevó a negar su propia homosexualidad, de la que nunca perdió la malignidad verbal que con tan elaborada saña descarga sobre sus antiguos amigos 
Masotta y Sebreli. Con todo, esto es apenas el preámbulo para entrar en tema : la manía en tanto defensa ante la guerra así como provisión de una doctrina para la guerra: "Escolarizados en y por la guerra, desembocamos en la manía intelectual argentina como fuente doctrinaria de la represión y del terrorismo represivo. Este es un aspecto de la guerra, y ésta, una expresión - a medias opaca, a medias transparente- de la lucha de clases en la Argentina" (44). Para Correas, entonces, la guerra es un aspecto de la lucha de clases y los intelectuales "escolarizados" por los militares a partir del 76 ignoran la realidad en que se actualiza esa guerra, adoptando "necesariamente el partido de la represión armada contra la subversión" (43) y transformándose en fuente doctrinaria de la represión.

7 Víctor Massuh y sus obras presentan diversas cualidades o modos que serán ofrecidos en grados: el primero es el grado de Antiguo, que "no habla siempre, pero, cuando habla, habla desde y para siempre" (45) ; es la voz encarnada del Espíritu y al mismo tiempo la del "gorila autorizado", cuya distinción, así como su estilo "confitadomohoso" (48), le permiten colocarse en el lugar de maestro educador de las masas (Correas utiliza aquí argumentos similares a los ya expuestos por Blas Matamoro sobre Mallea en Oligarquía y literatura de 1975) ya que la educación de las masas, sea para "ayudarlas" o para "vencer sus resistencias", es una subespecie de la manía intelectual argentina. En su segundo grado Massuh asciende -o desciende, para Correas da igual- a Primitivo Contemporáneo y Correas diseccionará con detalle de miniaturista una buena cantidad de frases de La libertad y la violencia, con las inevitables correcciones gramaticales y denuncias de citas inexactas de Marx, ya que "en Massuh hay una sacra ausencia de pruebas o, indiferentemente, la sacra demostración de un confidente con Lo Divino" (67). En esta fase, la manía del intelectual argentino radica en exhibir, a la defensiva, "un 'examen' de hecho beligerante contra el marxismo, y en recurrir al idealismo y a los sentimientos de 'religión' y 'patria”" (72). Si la tortura es o debería ser el tema privilegiado de la reflexión del intelectual, el primitivismo, "esto es, el júbilo desértico y zoquete de Víctor Massuh" (74) es aquí tan patente como el de la mala conciencia de la intelectualidad argentina, a partir de la cual surge otra interesante nota, la nota 66, "Sobre lo oficial". Correas adscribe el ensayo de Massuh a la tradición "vetusta" del essai-martyr francés de Breton, Leiris y Bataille, pues "la vetustez puede ser largamente contemporánea para los argentinos" (77) y agrega al Nietzsche de Ecce Homo, que en términos discursivos es de hecho una de las fuentes más plausibles del propio estilo de Correas ("Por qué soy tan sabio", "Por qué soy un destino", etc.). Un "honesto" cultor del ensayo mártir es para él Oscar Masotta, sobre el que aun no había escrito, y una oposición a este tipo de ensayo es la del "ensayo-magia" cultivado por Borges, hacia quien la admiración de Correas no claudica (cf. la nota 34 de La operación Massotta). Massuh llega luego al grado de "empírico extremo" para practicar esa "digresión plomiza" del ensayo-mártir que es el ensayo del malhumor que para Correas encarna de manera ejemplar Ezequiel Martínez Estrada, otro autor que peca de autodidactismo. Se equilibra Massuh en la cuarta fase como "el hermano Víctor" con modulaciones de un "entre nos" que a diferencia del de Mansilla "pertenece [...], primeramente, al verbalismo de las agrupaciones producidas por el terror en quienes no lo ejercitan, sino que lo padecen" (99), a lo que sigue otra ineludible nota, la 82, "sobre la injuria". Por motivos de espacio sólo podemos apenas mencionar la última fase, la del "resagrado", epíteto motivado por el afán de "resacralizar", de volver a lo sagrado con el que exhorta Massuh al "argentino medio" "y que a Correas le sirve para 
concluir de manera desconcertantemente obvia sobre la alianza entre Iglesia y Fuerzas Armadas.

8 No hace falta insistir en la importancia de este ensayo; su fuerza argumentativa y su "arte de injuriar" fácilmente permiten colocarlo junto a su compañero, ese otro notabilísimo sobre Masotta, e incluso ponerlos en diálogo para iluminar algunos intersticios cuyo sentido la sintaxis flamígera o la ironía al cubo de Correas a veces vuelven dificultoso. Pero su lectura independiente, su lectura ajena al "caso" Correas, es en sí misma ineludible en la genealogía del ensayo argentino de la que él mismo es un activo fustigador. En tal sentido nunca será suficiente el elogio a esta impecable edición emprendida conjuntamente por la Universidad Nacional de General Sarmiento y la Universidad Nacional de Córdoba, a la que pertenece el estudioso de su obra Carlos Surghi, cuyo epílogo firma.

9 Finalmente, también a instancias de la Universidad de General Sarmiento, el redescubrimiento correísta inaugurado en la primera década del siglo XXI por la editorial Interzona (con una edición de sus relatos -Un trabajo en San Roque, 2005, a cargo de Eduardo Rinesi y Jung Ha Kan- más prolija que la recién comentada de Mansalva, y en 2007 con la reedición de La operación Masotta) se completa con un volumen colectivo que reúne las intervenciones de unas jornadas dedicadas al autor organizadas por la misma universidad entre el 21 y 22 de mayo de 2009. Como cabe suponer, la calidad de los trabajos es diversa pero prevalece un nivel general más bien alto que quiere hacer justicia a la excelencia ensayística del homenajeado, aunque no logre deshacerse en algunos pocos casos de lugares comunes de la retórica académica de la que tanto abominaba Correas. No obstante, en general y tal como lo expresan los compiladores en el prólogo "lo que domina este conjunto de trabajos no es la actitud del burócrata que escribe su ponencia para sumar una línea a su currículum. Hay pasión y dedicación en muchas páginas de este libro" (DT 12). Las distintas secciones se ocupan de las facetas de Correas y de su obra: de la primera, "Correas crítico, traductor, profesor", se destaca el trabajo de María Pía López, que acierta al comentar que además de existencialista, "el método de Correas es [...] quizás [...] nietzscheano" (DT 25). El siguiente trabajo a cargo de Javier Fernández se centra en el Correas traductor pero resulta algo impreciso y no repasa exhaustivamente las traducciones emprendidas por Correas (sería interesante, por ejemplo, enterarnos por qué el exigente Correas se conformó con traducir a Kierkegaard del francés). La siguiente sección aborda el tema crucial de lo autobiográfico en Correas, donde se destacan los trabajos de Alejandro Boverio y Silvina Nora Labado. La sección dedicada al sartrismo de Correas es algo así como el núcleo significativo del volumen y presenta dos de los mejores trabajos de la compilación : el de María Gabriela D’Odorico y el de Leonardo Eiff, aun cuando los siguientes trabajos de Guillermo David y José Fraguas no le van en zaga. D’Odorico ofrece una reflexión muy completa de Carlos Correas como ensayista y narrador, indispensable para acercarse a su pensamiento, mientras que Eiff revisa de manera sobria y certera la influencia del Sartre literato y filósofo más que del intelectual en un Correas que asumirá esta filiación en su Arlt literato. Por otra parte Eiff da una clave para la cuestión del mal en Correas: "la práctica del mal es la única manera mediante la cual la libertad puede realizarse en el sujeto en el seno de la sociedad burguesa, por eso hay que reivindicar el mal como una forma extrema de crítica de la dominación burguesa ; tal fue el proyecto estético, filosófico y existencial que Correas mantuvo a lo largo de su vida [...]" (88). Fraguas hace un buen repaso de los comienzos de Carlos Correas en el contexto del existencialismo argentino de los años 
50. Aunque no es posible detenernos en cada trabajo, debe destacarse uno que capta muy bien los síntomas que produce la lectura de Correas, el de Laura Estrín, que entre otras cosas sostiene que "Correas no es silenciado, es desoído" (pp. 122-3). Jorge Quiroga, por su parte, lee la ficción de Correas en su filiación con las conciencias en crisis arltianas, en tanto que la doble naturaleza entre ficcional y ensayística de la escritura correísta es el punto de partida del valioso artículo de Miguel Vedda para revisitar los fundamentos filosóficos -en particular hegelianos- y literarios -en particular kafkianos- de su escritura.

La sección "El ser salvaje: deseos, cuerpos y cultura argentina" se presenta como el otro polo significativo del volumen con los excelentes aportes de Emilio Bernini, Eduardo Muslip y José Maristany. Bernini se detiene en las dificultades de la experiencia homosexual -y su representación- antes del mundo queer y traza las diferencias entre la manera de abordar el tema como problema estético en José Bianco, Manuel Mujica Láinez, Correas y más tarde Oscar Hermes Villordo o Pablo Pérez, aunque omite misteriosamente a todo un referente como Manuel Puig. Encara también Bernini la enigmática cuestión del abandono por parte de Correas de la homosexualidad para poder construirse como filósofo. José Maristany aborda en detalle la importancia entre los intelectuales argentinos del San Genet de Sartre para empezar a "pensar y verbalizar [...] la emergencia de una incipiente subjetividad homosexual" (217) y a continuación analizar esa influencia en los relatos "El revólver" y "La narración de la Historia".

11 Tanto los aportes de Alejandra Varela como los de Edith Elorza, Oscar Steimberg, Horacio González o la presentación que hace Jorge Lafforgue del entonces inédito "Los jóvenes” le permiten al lector acercarse a un Correas más íntimo o más personal que equilibra el registro académico del resto de los trabajos y termina de redondear un volumen de absoluta referencia para quienes en adelante se ocupen o se interesen por la obra de Correas. Gracias a iniciativas como éstas Carlos Correas seguirá ganando la visibilidad que merecen sus escritos y que él mismo y su accidentada carrera editorial no pudieron asegurar.

\section{NOTAS}

1. Ver más abajo los comentarios sobre Decirlo todo.

2. De hecho, La manía argentina comienza con la siguiente frase : "Desde marzo de 1976 nuestros militares han obrado un ascenso en el pueblo argentino al educarlo conceptualmente en y para la guerra", p. 17.

3. En Correas las notas al pie se plantean como abigarrados microensayos que no se pueden obviar.

4. La impresionante nota 88 sobre este tema, muy a la manera de Correas, introduce un paréntesis de ficción costumbrista que merece ser destacado. 


\section{AUTORES}

MARIANO GARCÍA

Escritor, UCA-CONICET 